\title{
Digital Storytelling: Teaching Aid for E-Learning to Improve the Quality of Non-Formal Students of Teachers' Training and Education
}

\author{
Syafrizal, Yayat Ruhiat, Sutrisno Sadji Evenddy \\ English Educational Department \\ Universitas Sultan Ageng Tirtayasa \\ Banten, Indonesia \\ syafrizal@untirta.ac.id
}

\begin{abstract}
This article discus about digital storytelling as supporting materials for the e-learning portal in students of NonFormal Department. It tells about the process to create a digital storytelling as teaching aid for literal listening subject. It has urgency to give contribution for the effective and fun English learning. Qualitative approach is used to analyze the data. The research started with collecting sources for creating the digital storytelling on stories entitled "Aunt "Polly" and "Tom Fight" by Mark Twain. It started from inventorying the teaching and learning stuff such as syllabus, lesson plan, software, and the digital contents of the storytelling made. The researchers choose Audacity 3.5 Beta, and Windows Moviemaker 2.6, as the software for editing audio and creating video. The stories are made for improving the students listening skills either bottom-up or top down. The result of this research proves digital storytelling can be used in E-learning portal, such as Edmodo. The questionnaires result shows that digital storytelling is an interesting material, but need to be modified more in e-learning.
\end{abstract}

Keywords-digital storytelling, audio and video files, e-learning

\section{INTRODUCTION}

Rapid technology development has changed students' style in learning. Today's students or those who were born after $21 \mathrm{st}$ century especially they which called "digital natives" are generation of learning that process information differently with parents or their teachers when they were in their age. Meanwhile, they who have the same age with adult or students' lecturers "digital natives" are called "digital-immigrant" who have to be able to learn and understand how new technology changes can potentially affect student's learning process. The concept of "pencil and notebook / laptop" considers rather odd to them than the concept of "computer and the web". Doing the assignment means to copy and paste the topics on the internet while writing activities are traditionally boring for them. Many experts agree that the generation of those students can improve their skills with quality e-learning material [1]. E-learning is one of the media that is prepared to anticipate changes on students' patterns and learning styles which associated with the development of information and communication technology. Therefore, preparing the material that will be presented to students in e-learning portal does not like to move the material from the textbook into a mere format. It requires creativity from the lecturers to prepare the material that can attract students' interest and according to students' learning style who tend to be different, and especially those that can utilize technology to the fullest. Digital technology which is considered as a form of third technological revolution after school as a form of first educational revolution in Socrates' time, and the invention of the printing press by Guttenburg as the early creation of the book as a form of second educational revolution, inspire many people to change old habits and conventional become a brand-new tradition all-digital [2]. The example of the impact of this third technological revolution can be found in our daily life such as digital clock, digital radio, television and other household devices also get the impact of this revolution.

One thing that attracts researcher's interest which is related with above explanations is to use a device known as Digital storytelling. As one of the media that restore the tradition of storytelling into latest form and format, which is in a video format that can be uploaded to video sharing media or through e-learning portal that has been provided, digital storytelling into one type of material that can increase students' interest in learning the material. The context of this research is in higher education and with the main purpose of using digital storytelling as an effective learning device. This research is expected to provide the following benefits: (1) For students, it can facilitate the understanding on the subject of digital technique; (2) For lecturer, this learning application will facilitate lecturers in delivering effective and fun learning in the classroom; (3) For department, it can give the input and consideration for department to develop and enhance teaching and learning activities using appropriate medias; (4) For university, the results of this research can be a source of material or reference for students in Sultan Ageng Tirtayasa University on research and for the development of instructional media as an advance research material, and (5) For researcher, the results of this research are expected to be used as material to broaden the discourse in the development of instructional media. 


\section{THEORETICAL FRAMEWORKS}

Digital technology has the potential to transform the learning experience into a number of very different ways, which include portability, flexibility, transferability, interchange ability, students' autonomy improvement, the development model of hyper textual of text production, recording and accessing meta-cognitive process, store ability and search information, improving learning opportunities partner, and a more comprehensive referencing facilities. Those whole potentials have the capacity to transform the learning process so that the development of knowledge can not only be achieved by means of more efficient but also changed qualitatively. Storytelling is the art of using language, vocalizations, and/or physical movement, and gesture, to reveal the elements and images of a story on a particular participant directly. Storytelling is the most effective educational devices from ever tested, which uses the skills possessed by almost everyone [3]. The writer has many ways to start the story in writing, while storytelling can improve spontaneously involving participants in the process of speaking. The word is chosen and arranged. The word chosen and arranged on a paper or presented verbally in an effort to attract attention of a group of readers or listeners, the effectiveness of the effort made depend on many factors such as the ability to transfer knowledge, experience and intuition into words and pictures which are interested to intended participants.

Digital storytelling is basically the practice of using computer-based tools to tell the story. Enthusiasm broadcaster deals with content ideas which is developed by the user to lead the emergence of an important community outside of the project such as the Center for Digital Storytelling which has been widely known in the international world [4]. There are various ways to use digital storytelling in learning. The first consideration that must be taken when deciding to use this device in the study is whether in these educators will make Digital storytelling or ask the student to do it as an assignment.

Referring to the video material via Coursera MOOC held by the Center for Digital storytelling as a pioneer of digital storytelling, there are three types of Digital storytelling namely: (1) Personal narratives, the stories which related to someone's personal records, especially about events that have significance for their life. (2) Historical Documentaries, a story that elevates the dramatic stories that help students be better to understand the past. (3) Content area stories, a story designed specifically to inform students about specific concepts they are studying or practitioner with a wide range of topics such as history, culture, mathematic, language, medicine, and others.

\section{METHOD}

The researcher used qualitative research. The data were collected through questionnaires from lectures and students who are interested in digital storytelling. The questionnaire is used to determine how respondents use digital storytelling for educational purposes. The subject of this research included participants who are interested or involved in the use of digital storytelling, including lecturers who use digital storytelling in the classroom. Questionnaire is one of the main instruments in this research. It includes six open-ended questions. These six questions are asked about whether or not "Aunt Polly" and "Tom's Fight" material are interesting for the students, appropriate for literal listening material, accurate to use online, is there any weakness, and it is appropriate for offline.

Open-ended questions were analyzed using open coding analysis technique [5]. Researchers identify the theme that emerged from the qualitative raw data included participants' answers to the question under "“Another"" category. During using open coding analysis technique, researchers created a descriptive and multi-dimensional category. The same category includes same words, phrases, and expressions.

Here are some steps that can be done to make Digital storytelling work to use for special learning as e-learning material for students, such as; determining the subjects, inventory of learning tools (syllabus, SAP, textbooks, etc) for the course, choose a topic and write a script, collecting digital sources such as pictures, audio / music, and video clips, select the content and create storyboards that show the factual information and textual, import, record and finalize. Import files that have been collected in step 2, start to record sound or narration using audio processing devices, and then finish making digital storytelling assignment, and the last step, and share or show to the others the result of the work that has been created by uploading them to the internet.

\section{DISCUSSION}

\section{A. Process in Making Storytelling}

\section{1) Literal listening inventory learning device}

The establishment of digital storytelling in this research relates to the use of digital media in the form of storytelling video to learn in Literal Listening subject in English Language Study Program curriculum academic year 2015/2016. Learning on this course is focused on activities that can improve students' listening skill in understanding oral discourse of English literal, which is related to the process of listening bottom up approach that focused on the ability of students in perceiving the sounds become words, words become sentences, and so on to the form of paragraphs, and the last discourse. In addition, students are also expected to be able to use their listening skill in top-down which is to know how far their background knowledge can be used to understand the discourse that they refer to.

\section{2) Determination of themes and competencies goal}

Relating with the competences and the topics that have been prepared by the lecturer of the literal listening course, researchers jointly determine the competence and what topics will be used as reference in making this digital storytelling. In this case the researchers only took four topics in two competencies in this literal listening syllabus course, the competences related to the ability to improve students' listening skill in a bottom-up with the topic of Aunt Polly and Tom's Fight, and which is relating with the ability to listen in top down which are Napoleon Bonaparte and Pompeii theme. 
3) Collecting digital files (audio, picture, video clip)

For the material under the title "Aunt Polly" and "Tom's Fight" researchers used audiobook of the novel entitled "The Adventures of Tom Sawyer" by Mark Twain, the novel in the form of recorded audio in $\mathrm{mp} 3$ format and downloaded from American English site. As for the material with the topic of Napoleon Bonaparte and Pompeii, researchers took from Listening Intermediate book which is included with audio CD, compiled by Phillip L. Lims and Susan Proctor. In addition to audio files of some of the themes that have been defined above, researchers collected pictures and clips (if any) that will be the visualization of digital audio narration in this storytelling.

\section{4) Preparing Processing Audio and Video Software}

There is some software used by researchers in constructing audio files and process the materials using a video processing device, or a video editor. To process the audio, researchers used audio software Audacity version 3 beta. The reason researchers used this software was one way to avoid the use of pirated software which is typically inserted by adware virus that can damage the computer and send the user to the risk of internet phishing and cybercrime, and especially because the price is very affordable for anyone.

\section{5) Processing Audio Files}

Relating with digital storytelling which was made in this research, researchers used the original or authentic narration read by English native speakers of audiobooks in audio files from intermediate modules listening book. Researchers' reason to take native speakers voice in order to make the students hear language model derived from authentic material for digital storytelling is created specifically for the learning to listen.

\section{6) Preparation of storyboards}

Storyboard is needed to compile the fragments of stories based on pictures used. Storyboard is compiled by the title of digital storytelling made.

\section{7) The process of Digital Storytelling video editing}

In making digital storytelling, basically, there are many applications that can be used. Researchers used Windows Moviemaker 2.6 a freeware downloaded from Microsoft's site in the establishment of digital storytelling which was the reason for this application free and easy to use.

\section{B. Online Literal Listening Lesson Plan with Using Digital Storytelling Material}

Researchers will explain about the design or online lesson plan of literal listening storytelling courses using digital material. Here are the steps:

\section{1) Determine the E-learning portal}

After preparing literal listening learning materials, researchers determined what e-learning portal that will be used for learning. In this case the researchers chose Edmodo as a free elearning. Edmodo is an e-learning portal that has a function as a social media which is free. Teachers or lecturers can register as a teacher and create a group or class as much as possible and with the number of participants as desired.

\section{2) Setting e learning portal}

After determining e-learning portal, researchers set up the e-learning portal. In this case participants (students and teachers) should have Edmodo accounts.

\section{3) Upload video to Youtube Channel}

In the trial of the material in the form of digital storytelling, researchers need a place to share videos, and the famous free video sharing is youtube.

4) Publishing digital storytelling materials through Edmodo

After finished with the process of uploading a digital storytelling video through Youtube, the next step is to publish such material through a virtual classroom/online courses Literal Listening on Edmodo e-learning portal.

5) Developing questionnaire through polling facilities on Edmodo

To know students' responses to the use of digital storytelling in literal listening subject, researchers can response students directly.

\section{Students' Responses Toward Digital Storytelling used in Literal Listening Through Portal Learning Edmodo}

Questionnaire consist of six question which is asking whether or not "Aunt Polly" and "Tom's Fight" material are interesting for the students, appropriate for literal listening material, accurate to use online, is there any weakness, and it is appropriate for offline. On the first question, regarding with students' opinion about the video entitled "Aunt Polly" the result of the questionnaire has been given to the students by the total 62 respondents, it was known that 7 (11.29\%) chose the response "Very Attractive", 46 (74.19\%) chose the response "Interesting", 8 (12.9\%) chose the response "Neutral", none $(0$, $00 \%$ ) chose the responses "not interesting", and only 1 person $(1.61 \%)$ who chose the response "It's not interesting". On the second question, according to respondents' opinion on "Tom's fight" video, from 60 respondents, 10 respondents $(16,67 \%)$ chose very attractive, 36 respondents $(60 \%)$ chose interesting, 13 respondents $(21.67 \%)$ chose neutral, 1 person $(1.67 \%)$ chose not interesting, and no one $(0 \%)$ chose strongly attractive. Therefore, based on the results of the questionnaire, digital video storytelling entitled Tom's Fight was interesting because 36 respondents from 62 respondents which $60 \%$ chose the response with interest.

The third question about which was related with digital storytelling material was highly appropriate in learning literal listening, from 65 respondents, 9 (13.85\%) respondents answered Strongly Agree, 42 respondents (64.62\%) chose agree, 11 people $(16.92 \%)$ chose undecided, 2 respondents $(3.08 \%)$ chose disagree, and 1 respondent $(1.54 \%)$ chose strongly disagree. Therefore, based on the results of the questionnaire, both of digital video storytelling was highly appropriate to use for literal listening because 42 respondents (64.62\%) from total 65 respondents chose Agree with the statement The fourth question which was relating with the use of online material explained that the results of questionnaires that have been obtained by researchers of the third question through a poll given in e-learning portal Edmodo note that 9 
respondents (13.85\%) from total 65 respondents chose Strongly Agree, 25 respondents (38.46\%) chose Agree, 18 respondents $(20.69 \%)$ chose undecided, 13 respondents $(20 \%)$ chose disagree, and no one $(0 \%)$ chose strongly disagree. Therefore, based on the results of the questionnaire, both storytelling digital video was not appropriate to use in literal listening because there were only $25(38.46 \%)$ from 65 respondents that agreed with the statement. Researchers need to reconsider the use of such material online.

On the fifth question, there were still a shortage of material that must be corrected, the results of questionnaires that have been obtained by researchers of the third question through a poll given elearning portal Edmodo note that from a total of 63 respondents, 5 respondents $(7.94 \%)$ chose strongly agree, 39 respondents $(61.9 \%)$ chose agree, 16 respondents $(25.4 \%)$ chose undecided, 3 respondents $(4.76 \%)$ chose disagree, and no one $(0 \%)$ chose strongly agree. Therefore, based on the results of the questionnaire of both digital storytelling video, it still needs a lot of improvement because 39 (61.9\%) from 63 respondents chose agree with the statement. Researchers need to improve the material to make it more attractive and perfect.

In the sixth question, digital storytelling was better to use offline than in language lab. Based on the result of questionnaires that have been obtained by researchers the third question through a poll given e-learning portal Edmodo note that $15(23,08 \%)$ from 65 respondents chose the answer strongly agree, 43 respondents $(66.15 \%)$ chose agree, 7 respondents $(10.77 \%)$ chose disagree and no one choose very disagree $(0 \%)$. Therefore, based on the results of the questionnaire that the researcher must reconsider the things that need to be improved and added to the second digital video storytelling to be eligible to be used as the material online for 49 respondents from a total of 65 respondents, amounting to $66.15 \%$ chose the response Agree with the statement. Researchers need to restore the material to make it more attractive and perfect.

\section{CONCLUSIONS AND SugGESTIONS}

\section{A. Conclusion}

Based on the result of research obtained in the form of a video file and also in the form of Digital Storytelling after passing through several stages of making digital storytelling, the researchers concluded that the process of making a video file of digital storytelling has been implemented properly so that the file can be used in order to prepare the portal eLearning, especially for establishing course or material in dealing with the material that has been made, such as Literal Listening subject.

Besides preparing the materials for the course digital storytelling literal listening, the researchers also set up elearning portal to students and faculty use online. In this case, Edmodo become a recommended option because it is free of charge, it is practical and easy. The use of digital media storytelling can be uploaded to Edmodo via YouTube.

In this study, the researchers also obtained data through questionnaires by exposing six questions distributed via online or offline. Based on the results of the questionnaire, it was concluded that most respondents liked the English language learning using digital storytelling, but the use of digital storytelling online must be improved to make it more attractive. Nonetheless, there are many obstacles when the researchers compiled this device such as 1) relating to the processing time is relatively short so that the results are less than the maximum, 2) lack of availability of image files that can represent the narrative, 3 ) other constraints of a technical nature workmanship digital video storytelling, and 3) the unavailability of e Learning portal so that researchers learning difficulties to the testing device is online.

\section{B. Suggestions}

Finally, based on the experience that has been done by researchers from preparation to the creation of digital media storytelling, there are several things to be taken into account, especially for users (user) and the maker (creator) which will consider the use of digital storytelling as a medium for effective learning to many subjects or materials. 1) create the video that will be used as attractive as possible so that the device can be attractive to students; 2) careful in selecting themes and images that represent them; and 3) remember the wise words "respect the work of others like you to respect your work yourself".

\section{REFERENCES}

[1] Repnik, Robert, Kaucic, Branko, \& Marjan, K. (2012). ELearning Theories, Design, Software and Applications. Croatia: Intech.

[2] Mota, Ronaldo, Scott, \& David. (2014). Education for Innovation and Independent Learning. USA: Elsevier Inc.

[3] Haven, Kendall , Ducey, \& Marygay. (2007). Crash Course in Storytelling in Higher Education Using Reflection and Experience to Improve Learning. London: Taylor and Francis ELibrary.

[4] Buckingham, D. (2009). A Common place Art, Understanding Amateur Media Production. In Video Cultures Media Technology and Everyday Creativity (pp. 23-50). Basingstoke, UK: Palgrave Macmillan.

[5] Strauss, J. C. (1990). Grounded Theory Research: Procedures,. Qualitative Sociology, 3-21. 